\title{
2022: A pivotal year for diagnosis and treatment of rare genetic diseases
}

Stephen F. Kingsmore

skingsmore@rchsd.org

Rady Children's Institute for Genomic Medicine, Rady Children's Hospital, San Diego, CA 92123; Keck Graduate Institute, Claremont Colleges, Claremont, CA 91711

The start of 2022 is an inflection point in the development of diagnostics and treatments for rare genetic diseases in prenatal, pediatric, and adult individuals - the theme of this special issue. We now know the molecular basis of 7,100 genetic diseases (https://www.omim.org/statistics/geneMap). International data sharing and genomic sequencing are greatly accelerating the identification of new, ultra-rare disorders (Osmond et al. 2022). We can diagnose a critically ill child with a genetic disease by rapid whole genome sequencing (WGS) in only 7 hours (Gorzynski et al. 2022). Over 500 childhood-onset genetic diseases have at least somewhat effective treatments (Owen et al. 2022; http://gtrx.rbsapp.net). Timely diagnosis by rapid WGS in critically ill newborns can save organs and lives with interventions as simple as dietary supplements (Owen et al. 2021). Real-world healthcare economic studies have shown that rapid WGS in regional intensive care units can save several thousand dollars per patient tested if turnaround time is short (Dimmock et al. 2021). A research-grade, thirty-fold coverage genome sequence now costs less than $\$ 400$ to generate, either by short-read sequencing-by-synthesis or long-read nanopore DNA sequencing (https://www.genome.gov/about-genomics/fact-sheets/DNA-Sequencing-Costs-Data). A patient-specific genetic therapy can be made from scratch and first administered within 13 months (Kim et al. 2019). As noted in a recent editorial, rapid WGS in critically III children has shifted from unease to evidence, education, and equitable implementation (Frank et al. 2021). Here I briefly review recent developments in the latter two aspects of rare genetic disease diagnostics and treatments.

\section{Equitable Implementation of Genomic Medicine}

Unfortunately, much remains to be done implement genomic medicine equitably. We are thankfully witnessing the demise of unenlightened policies that only cover outpatient genetic testing. Formerly, US physicians were required to discharge ill children with suspected genetic diseases from hospital to order outpatient molecular testing that their healthcare insurance would cover. The idiocy of this policy was exemplified in a recent study that found a sevenfold higher diagnostic rate with inpatient WGS compared with outpatient WGS (Thiffault et al. 2019).

I will never forget my first meeting with Sir Mark Caulfield, then the Chief Scientist of Genome England, in the early twenty-teens. I mentioned the need for further quantitative studies of the clinical utility and cost 
effectiveness of rapid WGS in hospitalized infants to accelerate reimbursement discussions. He declared that there was already sufficient evidence and the need, instead, was national implementation. Such thinking spurred the UK Secretary of State for Health and Social Care, Matt Hancock, to announce in 2018 that the National Health Service would be the first to provide diagnostic WGS to all seriously ill children with a suspected genetic disorder (https://www.genomicsengland.co.uk/matt-hancock-announces-5million-genomes-within-five-years/). Happily, this will also be policy in Germany in 2023 (https://dejure.org/gesetze/SGB V/64e.html). In the US, the first coverage policy for inpatient, diagnostic, rapid WGS was written by Bob Plass, Medical Director of Blue Shield - California in 2019 (https://www.blueshieldca.com/bsca/bsc/public/common/PortalComponents/provider/StreamDocume ntServlet?fileName=PRV WholeExome Sequen.pdf). His criteria for assessing when rapid exome or rapid WGS, with trio testing when possible, should be considered medically necessary for the evaluation of infants or children in intensive care with illness of unknown etiology, are excellent. Anthem, Blue Cross, and Blue Shield have since ratified this policy nationally. Genomic equity is starting to happen in the United States. Medicaid, the joint federal and state program that provides health coverage to nearly all lowincome Americans, including children, pregnant women, parents, seniors, and individuals with disabilities, is the largest source of health coverage in the US. In 2018, California Assemblymembers Brian Maienschein and Rob Bonta, co-chairs of the California Legislative Rare Disease Caucus, sponsored a bill that funded Project Baby Bear, a real-world implementation project of diagnostic, rapid WGS in critically ill Medicaid infants in five children's hospitals (Dimmock et al. 2021). Baby Bear was a success. It demonstrated that the clinical utility and cost effectiveness of rapid diagnostic WGS observed in research studies could be recapitulated in routine care in Medicaid infants (Dimmock et al. 2021). In response, the California legislature passed bills to make rapid diagnostic WGS a covered Medicaid benefit and provided funds to cover hospital costs of testing. While in 2022 this became policy, the California Department of Health authorized no reimbursement separate from the existing Diagnosis Related Group (DRG) payment to offset the incremental costs for hospitals to provide this new service (https://files.medical.ca.gov/pubsdoco/bulletins/artfull/ips202112.aspx). Since Medicaid reimburses only $90 \%$ of costs of hospital care, Medicaid beneficiaries in California still lack equitable access (https://www.aha.org/factsheets/2020-01-07-fact-sheet-underpayment-medicare-and-medicaid). In contrast, an almost identical project in Michigan, Project Baby Deer, resulted in a policy decision in 2021 by the Michigan Department of Health that authorized rapid diagnostic WGS with reimbursement separate from the DRG payment to hospitals (https://www.michigan.gov/documents/mdhhs/MSA 21-33 732848 7.pdf). Similar Baby Manatee and Baby Bambi implementation projects are in progress in Florida 
(https://www.floridatrend.com/article/32113/nicklaus-childrens-hospital-project-baby-manateeadvanced-genomics-cuts-diagnostic-delays-costs) and Israel (https://www.gov.il/en/departments/news/21102021-03). Finally, the "Precision Medicine Answers for Kids Today" provisions of the Cures 2.0 Act recently reintroduced to Congress would greatly accelerate equitable implementation in the US (https://www.congress.gov/bill/117th-congress/housebill/6000/text).

\section{Genomic Medicine Education}

For new entrants to the field of genome-informed medicine it is important to point out that rapid diagnostic WGS sequencing was not possible until 2012 (Saunders et al. 2012), and the first effectiveness study of this method was not published until 2014 (Soden et al. 2014). Since it takes a minimum of 10 years to train a medical subspecialist, we are still awaiting an influx of consultants whose formal training included genomic medicine. Medical textbooks, a definitive source of medical information, do not yet cover the topic of intravenous fluid replacement adequately, never mind genomic medicine, leading physicians at the University of Glasgow to lament: "Systematic revision of current textbooks might improve knowledge and practice by junior doctors. Careful definition of the remit and content of textbooks should be applied more widely to ensure quality, fitness for purpose, and avoid omission of vital knowledge" (Tez and Yildiz, 2017; Powell et al. 2014). In the interim, while genomic medicine curricula are designed and textbooks rewritten, education of healthcare providers is occurring by bootstrapping. Several such methods are proving effective. One is multidisciplinary, case-based learning that engages healthcare professionals in the process of making real-world patient decisions. We have been doing this almost weekly for five years (https://radygenomics.org/education). Initially case-based learning was in person. For the last three years, however, it has been wholly virtual - enabling unanticipated expansion to diverse, global audiences. The format is simple. A physician starts by presenting a recent case, sharing pertinent clinical findings in the order in which they were ascertained. The presentation is interactive, with participants asking branching questions. Case-based learning is a pedagogical approach that relies on a core premise of medical training: the use of our clinical knowledge, acumen, and experience to formulate a temporally dynamic list of differential diagnoses in every patient seen. Getting that list "right" and correctly ordered, predicated on the net prior probability of each disorder in each patient is considered a criterion of clinical excellence. For those who are not physicians, this is evidenced by searching PubMed for "formulating a differential diagnosis", which returns over 1,500 references or, alternatively, by watching 177 episodes of House, M.D.. In unstable patients, empiric therapy is started 
immediately. As test results are received, new features evolve, and responses to empiric treatment are observed, the Bayesian diagnostician recomputes net posterior probabilities, and re-orders the list.

Next in case-based learning, a laboratory director presents the diagnostic genome sequencing results, together with information regarding the genetic, pathologic, and clinical features of the disorder. When teaching, it is vitally important to avoid jargon and to provide a glossary of specialist terms and synonyms. It can be disheartening to be told "It's called a variant not a mutation". Again, discussion follows. Lastly, a physician presents the treatment regimen, patient response, and outcome. The latter is important since it is very motivating for healthcare learners. Final discussion occurs. The vital knowledge conveyed to physicians by case-based learning is rather simple: Rapid, comprehensive, diagnostic genomic sequencing is indicated early in the evaluation of all severely ill infants and children in whom the underlying etiology of illness is uncertain, and later in the evaluation of patients who are not responding typically to empiric treatment. The beautiful new reality is that rapid whole genome sequencing is increasingly being regarded as a homogeneous test to diagnose (or help rule out) 7,100 disorders (Dimmock et al. 2020). Hitherto this concept was restricted to the tricorder on Star Trek (Chan et al. 2019)!

Another bootstrapping method for equipping front-line physicians in the practice of genomic medicine is the provision of web-based, artificial-intelligence assisted, clinical decision support tools. For diagnosis, these include Phenomizer and PubCaseFinder (Köhler et al. 2009; Fujiwara et al. 2018). At pediatric grand rounds at Children's Mercy Hospital 10 years ago, I would enter clinical features of cases being discussed in Phenomizer on my cell phone and then impishly suggest ultra-obscure differential diagnoses that the hapless chief resident was unable to spell. One of the successes of this young journal has been to illustrate repeatedly the humbling phenomenon of phenotype expansion - new presentations of known genetic diseases that require fuzzy rather than Boolean logic in diagnostic decision support tools. Dr. Kristen Newby calls such cases the hoofbeats of colored zebras (Halle and Andrews, 1986). Physician-selected descriptors of childhood genetic disease cases only overlap 3\% of the clinical features of their genome sequencing based diagnosis (Clark et al. 2019). Natural language processing of electronic health records (EHR) can improve this fit five-fold (Clark et al. 2019). Phenotype expansion and its antecedent - very incomplete knowledge of the breadth of clinical presentations of childhood genetic diseases - are major reasons that focused tests are increasingly being replaced by disorder-agnostic WGS. Clinical decision support tools can help medicine escape the mindset of the fabled drunkard, who limited the search for his lost car key to under the lamp post because that was where the light was (Collins, 2006). Eric Topol has admonished that we need to expose doctors to artificial intelligence-based diagnostic tools and help 
them understand clinical features that are not recorded in the EHR cannot be computed ${ }^{31}$. Artificial intelligence, paradoxically, may drive a renaissance in recording a complete history and physical signs in the EHR. Another, newer type of clinical decision support tool that is emerging for rare genetic disease is in therapy guidance. Systems such as Genome-to-Treatment help alleviate the unsupportable burden of searching and synthesizing the published treatment literature in rare genetic disease cases, many of which front-line physicians may have never encountered previously (Owen et al. 2022).

\section{Summary}

2022 will be an important year in the development of diagnostics and treatments for rare genetic diseases in prenatal, pediatric, and adult individuals. This perspective did not do justice to the breadth of clinical decision support tools, implementation projects, or legislative coverage decisions that are underway. Please write to me with details of those I missed, and I will update this piece. Meanwhile, in the words of Fred "Lyons, "The children are waiting" (https://scholarlyexchange.childrensmercy.org/cgi/viewcontent.cgi?article=1003\&context=recent histo ry).

\section{Acknowledgments}

Many thanks to Hilger Ropers, Elaine Mardis, Wendy Benson and Russell Nofsinger for suggestions that greatly improved this perspective. A Deo lumen, ab amicis auxilium.

\section{Funding}

SFK is supported by research grants from NIH (U01TR002271 to JM Davis and JL Maron, U54TR002359 to EJ Topol, and R01HD101540 to SFK and CD Chambers), Takeda, and Rady Children's Hospital.

\section{References}

Chan J, Raju SC, Topol E. 2019. Towards a tricorder for diagnosing paediatric conditions. Lancet 394: 907. Clark MM, Hildreth A, Batalov S, Ding Y, Chowdhury S, Watkins K, Ellsworth K, Camp B, Kint Cl, Yacoubian C, et al. 2019. Diagnosis of genetic diseases in seriously ill children by rapid whole-genome sequencing and automated phenotyping and interpretation. Sci Trans/ Med 11: eaat6177.

Collins FS. 2006. 2005 William Allan Award address. No longer just looking under the lamppost. Am J Hum Genet 79: 421-6. 
Dimmock DP, Clark MM, Gaughran M, Cakici JA, Caylor SA, Clarke C, Feddock M, Chowdhury S, Salz L, Cheung C, et al. 2020. An RCT of Rapid Genomic Sequencing among Seriously III Infants Results in High Clinical Utility, Changes in Management, and Low Perceived Harm. Am J Hum Genet 107: 942-952.

Dimmock D, Caylor S, Waldman B, Benson W, Ashburner C, Carmichael JL, Carroll J, Cham E, Chowdhury S, Cleary J, et al. 2021. Project Baby Bear: Rapid precision care incorporating rWGS in 5 California children's hospitals demonstrates improved clinical outcomes and reduced costs of care. Am J Hum Genet 108: 12311238.

Franck LS, Dimmock D, Hobbs C, Kingsmore SF. 2021. Rapid whole-genome sequencing in critically III children: shifting from unease to evidence, education, and equitable implementation. J Pediatr 238:343.

Fujiwara T, Yamamoto Y, Kim JD, Buske O, Takagi T. 2018. PubCaseFinder: A Case-Report-Based, Phenotype-Driven Differential-Diagnosis System for Rare Diseases. Am J Hum Genet 103: 389-399.

Gorzynski JE, Goenka SD, Shafin K, Jensen TD, Fisk DG, Grove ME, Spiteri E, Pesout T, Monlong J, Baid G, et al. 2022. Ultrarapid Nanopore Genome Sequencing in a Critical Care Setting. N Engl J Med. Jan 12.

Halle AA 3rd, Andrews MD. 1986. Hoofbeats of a zebra in the emergency room. Hosp Pract $21: 124 \mathrm{H}$.

Kim J, Hu C, Moufawad El Achkar C, Black LE, Douville J, Larson A, Pendergast MK, Goldkind SF, Lee EA, Kuniholm A, et al. 2019. Patient-Customized Oligonucleotide Therapy for a Rare Genetic Disease. N Engl J Med 381: 1644-1652.

Köhler S, Schulz MH, Krawitz P, Bauer S, Dölken S, Ott CE, Mundlos C, Horn D, Mundlos S, Robinson PN. 2009. Clinical diagnostics in human genetics with semantic similarity searches in ontologies. Am J Hum Genet 85: 457-64.

Osmond M, Hartley T, Johnstone B, Andjic S, Girdea M, Gillespie M, Buske O, Dumitriu S, Koltunova V, Ramani A, et al. 2022. PhenomeCentral: 7 years of rare disease matchmaking. Hum Muta Feb 14.

Owen MJ, Lefebvre S, Hansen C, Kunard CM, Dimmock DP, Smith LD, Scharer G, Mardach R, Willis MJ, Feigenbaum A, et al. 2022. An automated 13.5 hour system for scalable diagnosis and acute management guidance for genetic diseases. Nat Commun In Press.

Owen MJ, Niemi AK, Dimmock DP, Speziale M, Nespeca M, Chau KK, Van Der Kraan L, Wright MS, Hansen C, Veeraraghavan N, et al. 2021. Rapid Sequencing-Based Diagnosis of Thiamine Metabolism Dysfunction Syndrome. N Engl J Med 384: 2159-2161. 
Powell AG, Paterson-Brown S, Drummond GB. 2014. Undergraduate medical textbooks do not provide adequate information on intravenous fluid therapy: a systematic survey and suggestions for improvement. BMC Med Educ 14: 35.

Saunders CJ, Miller NA, Soden SE, Dinwiddie DL, Noll A, Alnadi NA, Andraws N, Patterson ML, Krivohlavek LA, Fellis J, et al. 2012. Rapid whole-genome sequencing for genetic disease diagnosis in neonatal intensive care units. Sci Transl Med 4: 154ra135.

Soden SE, Saunders CJ, Willig LK, Farrow EG, Smith LD, Petrikin JE, LePichon JB, Miller NA, Thiffault I, Dinwiddie DL, et al. 2014. Effectiveness of exome and genome sequencing guided by acuity of illness for diagnosis of neurodevelopmental disorders. Sci Transl Med 6: 265ra168.

Tez M, Yildiz B. 2017. How Reliable Are Medical Textbooks? J Grad Med Educ 9: 550.

Thiffault I, Farrow E, Zellmer L, Berrios C, Miller N, Gibson M, Caylor R, Jenkins J, Faller D, Soden S, et al. 2019. Clinical genome sequencing in an unbiased pediatric cohort. Genet Med 21: 303-310.

Topol EJ. 2019. Deep Medicine: How Artificial Intelligence Can Make Healthcare Human Again. Basic Books, New York, NY. 


\section{COLD SPRING HARBOR Molecular Case Studies}

\section{2: A pivotal year for diagnosis and treatment of rare genetic diseases}

Stephen F Kingsmore

Cold Spring Harb Mol Case Stud published online February 25, 2022

Access the most recent version at doi: $10.1101 /$ mcs.a006204

Published online February 25, 2022 in advance of the full issue.

Accepted Peer-reviewed and accepted for publication but not copyedited or typeset; accepted

Manuscript manuscript is likely to differ from the final, published version. Published onlineFebruary 25,2022 in advance of the full issue.

Creative This article is distributed under the terms of the

Commons http://creativecommons.org/licenses/by-nc/4.0/, which permits reuse and

License redistribution, except for commercial purposes, provided that the original author and source are credited.

Email Alerting Receive free email alerts when new articles cite this article - sign up in the box at the Service top right corner of the article or click here. 